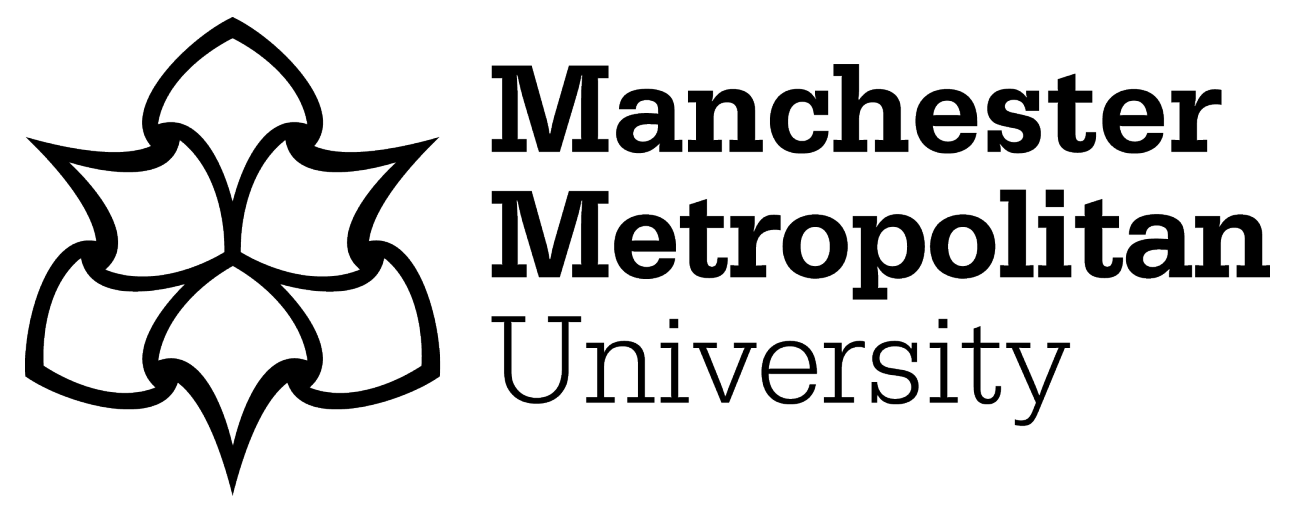

Wilkinson, Samantha (2018) Young People, Alcohol, and Urban Life. Oxford Bibliographies.

Downloaded from: https://e-space.mmu.ac.uk/621835/

Publisher: Oxford University Press

DOI: https://doi.org/10.1093/OBO/9780199791231-0206

Please cite the published version 


\section{Young People, Alcohol and Urban Life}

Dr Samantha Wilkinson, School of Science and the Environment, Manchester Metropolitan University

\section{Introduction}

Alcohol consumption, and particularly young people and drinking, have, for a long time, been the focus of popular, policy and academic work. This article will introduce the reader to dominant themes and areas of interest from international and interdisciplinary scholarship regarding young people, alcohol and urban life. This bibliography begins by detailing texts that provide *general overviews* of young people, alcohol and urban life. It then lists and discusses useful "reference works", ${ }^{*}$ book $^{*}$ and *journals*. The paper then moves on to discuss sources thematically, beginning with *young people, alcohol and gender*. This is important because, whilst drinking is typically thought to be male dominated, young women's alcohol consumption has increased in recent years. The article then moves on to explore *spaces of drinking*. Academic work on alcohol consumption has tended to be concerned with inner-city drinking, typified by a large body of work on the night-time economy. This paper introduces literature that provides insight into the diversity of indoor and outdoor drinking spaces, including: homes, pubs, streets, and parks. Moreover, recent years have seen an interest in moving beyond drinking spaces as static and bounded, to appreciate the importance of young people's movement in, through, and beyond, drinking spaces; this is the focus of the next section on *young people's urban im/mobilities*. Finally, recognising that friendships, and relationships with siblings and parents, can influence alcohol consumption practices and experience, the paper concludes with a consideration of *relational drinking practices*.

\section{General Overviews}

The topic of young people, alcohol and urban has attracted interdisciplinary attention. A number of texts focus on young people, others on alcohol, and others still on urban spaces; sources synthesising these bodies of literature are rare. Evans' 2008 paper offers an excellent overview of geographical engagement with children and young people. Furlong 2009 adopts an international and interdisciplinary lens to provide a useful overview of academic engagements with young people. Though not necessarily with an urban focus, Newburn and Shiner 2001 and Saunders and Ray 2011 offer comprehensive reviews of academic engagements with young people and alcohol. Perhaps the most prolific writers on social and cultural perspectives of alcohol are Jayne et al 2006; 2008a/b; and 2010. These papers each provide an excellent overview of work by social scientists on alcohol, drinking and drunkenness, and each of the papers highlights the agentic capacities of drinking spaces. A few papers work at the intersection of young people, alcohol and urban life. For instance, Chatterton and Hollands write extensively on the night-time economy, and their 2002 paper offers a useful overview of young people's consumption in urban drinkscapes. Somewhat differently, Wilkinson's 2015 paper moves beyond the night-time economy, to provide a useful review of literature on young people, drinking and urban spaces, highlighting the diversity of indoor and outdoor drinkscapes. 
Chatterton, Paul, and Robert Hollands. "Theorising Urban Playscapes: Producing, Regulating and Consuming Youthful Nightlife City Spaces". Urban Studies 39. 1 (2002): 95-116. doi: 10.1080/00420980220099096

This article develops a theoretical understanding of the relationship between young people and spaces within cities. The focus is on 'urban playscapes'; that is, young people's activities in bars, pubs, clubs and music venues within the night-time entertainment economy. The paper argues that production, consumption and regulation combine to create a dominant mode of 'mainstream' urban nightlife, with 'alternative' nightlife increasingly marginalised.

Evans, Bethan. "Geographies of Youth/Young People". Geography Compass 25 (2008): 1659-1680. doi: 10.1111/j.1749-8198.2008.00147.x

This paper highlights that children's geographies is a vibrant subdisciplinary area and geographical work on children and young people is making important contributions to academic and policy debates within, and beyond, the discipline of geography. This article reviews the position of young people in geographical research through interrogating the definition of young people in relation to children and adults, and reviewing literature on youth transitions.

Furlong, Andy. Handbook of Youth and Young Adulthood: New Perspectives and Agendas. London: Routledge. 2009.

This Handbook is written by leading academics from several countries, and introduces contemporary perspectives on issues affecting youth and young adults. The Handbook provides a multi-disciplinary overview, with a target audience of academics, students, researchers and policy-makers. The Handbook highlights key theoretical perspectives used within youth studies, and outlines areas for future research.

Jayne, Mark, Sarah Holloway, and Gill Valentine. "Drunk and Disorderly: Alcohol, Urban Life and Public Space". Progress in Human Geography 304 (2006): 451-468. doi: 10.1191/0309132506ph618oa

This paper argues that, in the existing literature, the relationship between alcohol, drunkenness and public space has been treated in a largely atheoretical manner. The paper focuses on the UK, and highlights the need for a research agenda underpinned by a more specific consideration of urban drinking. The authors argue that such a project must seek to gain a more nuanced understanding of the social relations and cultural practices associated with the emergence of particular types of urban drinkscapes. 
Jayne, Mark, Gill Valentine, and Sarah Holloway. The Place of Drink: Geographical Contributions to Alcohol Studies. Drugs: Education, Prevention and Policy 153 (2008a): 219-232. doi: 10.1080/09687630801969465

An exploration of how geographies of alcohol, drinking and drunkenness have been considered within, and beyond, the discipline of geography. The paper shows that geography, due to its sound theoretical engagements with space and place, has much to offer future alcohol studies research agendas.

Jayne, Mark, Gill Valentine, and Sarah Holloway. Geographies of Alcohol, Drinking and Drunkenness: A Review of Progress. Progress in Human Geography 322 (2008b): 247-263. doi: 10.1177/0309132507087649

A demonstration of how human geographers are approaching alcohol, drinking and drunkenness. That is, via complex interpenetrations of political, economic, social, cultural and spatial issues and unpacking connections, similarities, differences and im/mobilities between (supra)national, regional and local spatial scales. The paper is important in highlighting that this approach offers a conceptually and empirically important contribution to alcohol studies research.

Jayne, Mark, Gill Valentine, and Sarah Holloway. "Emotional, Embodied and Affective Geographies of Alcohol, Drinking and Drunkenness". Transactions of the Institute of British Geographers 354 (2010): 540-554. doi: 10.1111/j.1475-5661.2010.00401.x

This paper works at the intersection of geographers' engagement with emotion, embodiment and affect, and geographical research on alcohol, drinking and drunkenness. The paper highlights there has been an ontological and epistemological impasse in the existing literature between approaches considering the biological, physiological and psychological impacts of the consumption of alcohol, and those focusing on social and cultural practices. The paper addresses this impasse, by signalling the possibility of a more nuanced approach

Newburn, Tim, and Michael Shiner. Teenage kicks? Young People and Alcohol: A Review of the Literature. York: Joseph Rowntree Foundation / York Publishing Service. 2001

A comprehensive literature review, which engages with the ambiguities of alcohol. The review recognises that on the one hand, young Britons grow up in a culture in which drinking alcohol is widespread and socially acceptable. Yet, on the other hand, 'excessive' drinking is increasingly linked to various forms of anti-social behaviour. The review questions the appropriateness of legislative approaches, arguing that a combination of 'situational' and 'social' prevention initiatives offer a plausible way forward. 
Saunders, John, and Joseph Rey. Young People and Alcohol: Impact, Policy, Prevention, Treatment. Oxford: Wiley-Blackwell. 2011

Written by an internationally renowned team of contributors, this text offers a practical reference for professionals and researchers in the field of alcohol (mis)use, who engage with people aged 12 to 25 years. The book provides up-to-date information about the impact of alcohol consumption on young people, and explores how the use of alcohol can be managed.

Wilkinson, Samantha. "Young People, Alcohol and Urban Life". Geography Compass 93 (2015): 115126. doi: $10.1111 / \mathrm{gec} 3.12194$

This paper moves beyond the current academic pre-occupation with the night-time economy and drinking venues, to highlight the specificities of outdoor drinking cultures in streets and parks. Instead of viewing outdoor drinking as morally transgressive - as promoted in the popular press - the paper is important in highlighting that outdoor drinkscapes are distinctly appealing over commercial premises for some young urbanites.

\section{Reference Works}

There is one key reference work, which is updated regularly, and offers a sound contemporary resource on young people; this is Skelton 2015. Specifically, the section, titled: Geographies of Children and Young People. Play, Recreation, Health and Well-being, offers a comprehensive literature review on how young people regulate their well-being in different drinking spaces.

Skelton, Tracey. (Ed.) Geographies of Children and Young People. Singapore: Springer. 2015

This reference work comprises twelve volumes, and brings together innovative international scholarship focusing on younger people. Volumes one to three critically engage with the theoretical and methodological groundings of this geographical sub-discipline. Volumes Four to Eleven provide in-depth analysis of key topics related to children's and young people's lives, including: identities and subjectivities; and learning and labouring. Volume 12 connects academic, policy and practitioner based work around protection and provision.

\section{Books}

There are a number of interesting books, including Holt 2010 and Holloway and Valentine 2000, which provide sound insight into theoretical debates surrounding young people. With a focus on young adults, Smith 2014 focuses specifically on the night-time economy as an important arena for the performance of identities. Moving beyond a preoccupation with the night-time economy, Jayne and Valentine 2011 and Thurnell-Read 2015 shed light on the importance of a more diverse range of spaces and places for alcohol consumption practices and experiences. Very recently, Shaw 2018 has focused on cities at night, and the diverse range of practices that take place within the nocturnal city, one such practice being alcohol consumption. With a focus on drug consumption, as opposed to alcohol consumption, 
Malbon's 1999 provides an exciting ethnographic account of clubbing, and the impact of atmospheres of club spaces, when bound up with drug consumption.

Holt, Louise. (Ed.) Geographies of Children, Youth and Families: An International Perspective. London: Routledge. 2010

This edited book provides an introductory overview of current conceptual and theoretical debates surrounding geographies of children, youth and families, and gives a wide range of examples of cutting-edge research from a variety of international contexts.

Holloway, Sarah, and Gill Valentine. (Eds.) Children's Geographies: Playing, Living, Learning. London: Routledge. 2000

Drawing on original research and extensive case studies in Europe, North and South America, Africa and Asia, this book analyses children's experiences of playing, living and learning. The diverse case studies include a historical analysis of gender relations in 19th century North American playgrounds, and children's experiences of after school care in contemporary Britain.

Jayne, Mark, and Gill Valentine. Alcohol, Drinking, Drunkenness: (Dis)Orderly Spaces. Farnham Ashgate Publishing. 2011

Designed as a reference text, this book offers a systematic overview of geographies of alcohol, drinking and drunkenness. It explores the role of alcohol, drinking and drunkenness in people's lives, and investigates the ways in which spaces and places are key constituents of alcohol consumption. It also offers and examination of the economic, political, social, cultural and spatial practices and processes bound up with the consumption of alcohol.

Malbon, Ben. Clubbing: Dancing, Ecstasy and Vitality. London: Routledge. 1999

A very interesting ethnographic study exploring the cultures, and spaces, of clubbing in the late 1990s in Britain. The book brings to the fore issues surrounding sexuality and gender; the influence of music; and the role of ecstasy in clubbing experiences.

Thurnell-Read, Thomas. (Ed.) Drinking Dilemmas: Space, Culture and Identity (Sociological Futures). Oxon: Routledge. 2015

This edited book is interested in recognising that drinking and drunkenness are associated with contesting notions of responsibility, discipline and risk, and with positive aspects, such as: sociability, belonging, and identity construction. The volume collates the work of researchers from the UK, and beyond, to highlight the socio-cultural importance of contemporary drinking practices. 
Shaw, Robert. The Nocturnal City. Taylor \& Francis. 2018

This book looks at the relationship between night and society in contemporary cities. The book's fundamental premise is that: understanding what takes place at night in cities can add nuance to debates on urbanisation. The book explores a variety of practices and spaces encountered in the night-time city, including: nightlife and the night-time economy.

Smith, Oliver. Contemporary Adulthood and the Night-Time Economy. New York: Palgrave Macmillan 2014

An examination of the experiences of drinkers, who are at the forefront of the new night-time leisure industries, that have fundamentally changed the way we think about city centres. The book utilises the night-time leisure economy as a lens through which to view the relationship between global consumer capital. and the erosion of 'traditional' adulthood.

\section{Journals}

The topic of young people, alcohol and urban life, is multi-disciplinary. Moreover, there is no one singular journal dedicated to youth, drinking and urban living. Consequently, articles tend to be published in either youth-focused journals, such as *Children's Geographies*; *Journal of Youth Studies*, "Youth \& Society", and *Young*; or urban focused journals, such as *Urban Studies*. Articles focusing on young people, drinking and urban life, are also published in journals such as *Body \& Society", "Emotion, Space and Society*, and *Health \& Place*. Such journals offer outlets to bring to the fore the embodied, emotional and affective aspects of young people's drinking, and emphasise that spaces and places are not passive backdrops to drinking, but active agents with the capacity to shape drinking practices and experiences. There are a number of alcohol-focused journals, yet some are more biomedical, downplaying the social and cultural importance of drinking for young people; journals addressing this neglect include *Drugs \& Alcohol Today*, and *Substance Use \& Misuse*.

*Body \& Society[http://journals.sagepub.com/home/bod] ${ }^{*}$.1995-.

Committed to theoretical openness, this journal encourages publications that offer critical approaches to the body. It also encourages the development of innovative trans-disciplinary work related to the body and society.

${ }^{*}$ Children's Geographies[https://www.tandfonline.com/toc/cchg20/current] ${ }^{*} 2003-$.

An international, peer-reviewed, journal, publishing cutting-edge research and scholarship relating to children, young people and families. The journal actively encourages submissions beyond the discipline of geography, also provides a forum for policy-makers and practitioners. 
*Drugs \& Alcohol Today[https://www.emeraldinsight.com/loi/dat]" 2001-.

This journal aims to expose the causal links between policy and different health and public safety problems. The journal considers 'drug problems' internationally as a product of prohibitionist policies as much as of the drugs themselves.

*Emotion, Space \& Society[https://www.journals.elsevier.com/emotion-space-and-society] ${ }^{*} 2008$-.

A forum for multidisciplinary and interdisciplinary debates on theoretically informed research on the emotional intersections between people and places. Papers investigate feelings and the role of affect in various socio-spatial contexts. Emotions, embodied and affect are taken very seriously, as central to all human interactions with each other, and the worlds in which we live.

*Health \& Place[http://www.journals.elsevier.com/health-and-place] ${ }^{*} 1995-$.

An interdisciplinary journal dedicated to the study of health and health care, in which space and place are of fundamental importance. Readers are introduced to comparative perspectives on the role space and place makes to factor such as: the incidence of ill-health, and the development of health policy.

*Journal of Youth Studies[https://www.tandfonline.com/toc/cjys20/current] ${ }^{*}$ 1988-.

An international scholarly journal interested in theoretical and empirical understandings of young people's experiences and everyday lives. It is the leading multidisciplinary journal for academics with interests surrounding youth and young adulthood.

*Substance Use \& Misuse[https://www.tandfonline.com/toc/isum20/current*] 1996-., formerly known as International Journal of the Addictions, 1966 - 1995.

An international, multidisciplinary, arena for the exchange of research, theories, viewpoints, and topical issues relating to substance (mis)use. Topics covered include: clinical trials and research; epidemiology of substance misuse; and systematic reviews of interventions.

*Urban Studies[http://journals.sagepub.com/toc/usja/1/1]* 1964-.

A leading, multi-disciplinary, international journal for urban scholarship. This high impact journal is at the forefront of intellectual and policy debates on the urban spaces. 
*Young: Nordic Journal of Youth Research[https://in.sagepub.com/enin/sas/journal/young\#description] $]^{*}$ 1993-.

This journal brings young people's experiences to the fore, and promotes multidisciplinary youth research, from international perspective. It is interested in both contemporary and historical understandings of young people. It is a resource for not only academics and students, but also those working with young people.

*Youth \& Society[http://journals.sagepub.com/home/yasa]* 1969-

A long-standing, multi-disciplinary, peer-reviewed journal, which focused on issues related to 10-24 year olds, from both quantitative and qualitative methodological perspectives.

\section{Young People, Alcohol and Gender}

Drinking has typically been considered a 'male domain', thought to be male dominated, male identified, and male centered. The role of alcohol in young men's performances of masculinity is the focus of Mullen et al. 2007, and De Visser et al. 2007. Whilst drinking and drunkenness have conventionally been considered masculine behaviours, commentators have argued that young women's alcohol consumption has increased in recent years. Bailey et al. 2015 and Griffin et al. 2013 explore young women's performances of femininity whilst consuming alcohol. The focus of MacNeela and Bredin 2011 is to explore how young women regulate their drinking practices. Lyons and Willott 2008 take a more relational perspective, highlighting how young women define their gendered drinking identities in relation to young men. Bringing in a spatial dimension, Bancoft 2013 explores home drinking and club drinking for young women. Likewise highlighting the importance of space and place, Holloway et al. 2009 tease out gendered similarities and differences in drinking spaces, and practices.

Bailey, Lin, Christine Griffin, and Avi Shankar. "'Not a Good Look”: Impossible Dilemmas for Young Women Negotiating the Culture of Intoxication in the United Kingdom". Substance Use \& Misuse 506 (2015): 747-758. doi: 10.3109/10826084.2015.978643.

This paper investigates young women's alcohol consumption experiences in the United Kingdom. The paper draws on interviews with young white working and middle-class women, to explore how they inhabit the dilemmas of contemporary femininity in youth drinking cultures. Attention is given to how women aim to achieve the 'correct' form of hypersexual femininity, and the desired level of drunkenness. 
Bancroft, Angus. "Drinking With and Without Fun: Female Students' Accounts of Pre-Drinking and ClubDrinking". Sociological Research Online 174 (2013): doi: 10.5153/sro.2785

An engagement with female students' accounts of both pre-drinking and club-drinking. The paper argues that pre-drinking has a fundamental purpose for young women in managing risk, as well as ensuring a shared level of intoxication in preparation for accessing public drinking spaces.

De Visser, Richard, and Jonathan Smith. "Alcohol Consumption and Masculine Identity among Young Men". Psychology \& Health 225 (2007): 595-614. doi: 10.1080/14768320600941772

Drawing on both interviews and group discussions, the paper explores how young men's drinking practices are related to their notions about masculinity, and the role of drinking to their masculine identities. The paper signposts implications for health education and health promotion.

Griffin, Christine, Isabelle Szmigin, Andrew Bengry-Howell, Chris Hackley, and Wilm Mistral. "Inhabiting the Contradictions: Hypersexual Femininity and the Culture of Intoxication Among Young Women in the UK". Feminism \& Psychology 232 (2013):184-206. doi: 10.1177/0959353512468860

Through exploring young women's consumption of alcohol, this paper contributes to debates on post-feminism and the constitution of contemporary femininity. Femininity is viewed as a contradictory space, and the paper consider the ways in which young women inhabit this terrain, and the implications for contemporary feminism and safe drinking initiatives.

Holloway, Sarah, Gill Valentine, and Mark Jayne. "Masculinities, Femininities and the Geographies of Public and Private Drinking Landscapes". Geoforum 405 (2009): 821-831.

The paper addresses the paucity of research on gender and alcohol, beyond a narrow range of public drinking spaces, by exploring men and women's alcohol consumption in private and diverse public drinking spaces. In so doing, the paper highlights the importance of gendered moralities in shaping differences in alcohol consumption practices, spaces, and motivations.

Lyons, Antonua, and Sara Willott. 2008. "Alcohol Consumption, Gender Identities and Women's Changing Social Positions". Sex Roles 59 9-10 (2008): 694-712. doi: 10.1007/s11199-008-9475-6

In the context of Auckland, New Zealand, the paper offers an exploration of the ways in which women are (re)defining their gender identities in relation to men through alcohol consumption. The findings are discussed in terms of women's changing positions socially, and the success of gender identities through local communities of practices. 
MacNeela, Padraig, and Bredin, Olwen. "Keeping Your Balance: Freedom and Regulation in Female University Students' Drinking Practices". Journal of Health Psychology. 162 (2011): 284-293. doi: $10.1177 / 1359105310372977$

The paper draws on interviews and focus groups with female, binge drinking, university students. The authors highlight that the consumption of alcohol was associated with freedom, but also regulated by group norms. Drinking excessively was stigmatised by participants, and considered a means of abusing freedoms. The paper highlights that the harms of drinking are managed through trivialisation.

Mullen, Kenneth, Jonathan Watson, Jan Swift, and David Black. "Young Men, Masculinity and Alcohol". Drugs: Education, Prevention and Policy. 142 (2007): 151-165. doi: 10.1080/09687630600997816

This paper offers an identification of how young men's patterns of alcohol consumption are related to their notions about masculinity, and the importance of alcohol consumption to the performance of their masculine identities. The paper teases out conflicting perspectives between participants; whilst some young men considered drinking a marker of masculinity, others emphasised the importance of other behaviours, such as sporting success, to masculine identity.

\section{Spaces of Drinking}

The contemporary geographical imaginary of drinking is predominantly one of a city centre issue, typified by a large body of work on the night-time economy. There has recently been a surge of literature seeking to move beyond commercial drinking spaces, to highlight the diversity of drinking spaces. Barton and Husk 2014 highlight the importance of the space of the home for consuming alcohol, prior to accessing preformed drinking spaces. The private space of the home is also the focus of Foster and Heyman 2013 and Holloway et al. 2008. Demant and Landolt 2014 and Galloway et al. 2007 highlight the importance of outdoor drinkscapes, such as streets, for young people's alcohol consumption practices and experiences. In a number of geographical contexts, street drinking has been banned, and Pennay and Room 2012 seek to highlight the (in)effectiveness of such regulations. Townshend and Roberts 2013 look specifically at parks as drinkscapes, and the authors investigate young people's conflicting perceptions on the park as a space for drinking. Duff 2012 importantly highlights that drinking spaces are not passive backdrops to drinking practices; they are active agents, with the capacity to shape drinking experiences. Wilkinson 2015 offers a synthesis of international literature on the diversity of drinking spaces, and highlights how young people manage their well-being in such spaces. 
Barton, Adrian, and Kerryn Husk. "“I don't Really Like the Pub [...]": Reflections on Young People and Pre-Loading Alcohol”. Drugs \& Alcohol Today. 142 (2014); 58-66. doi: 10.1108/DAT-12-2013-0055

A discussion of the UK's shift from the traditional 'pub-club' drinking pattern, to a 'homepub-club' pattern. Drawing on in-depth interviews with young people, the paper enhances understandings of why pre-drinking is an entrenched aspect of their drinking cultures. The paper shows that many young people utilise alcohol as a means of coping with the Night Time Economy; they prefer the safety and control offered by home drinking.

Demant, Jakob, and Sara Landolt. "Youth Drinking in Public Places: The Production of Drinking Spaces in and Outside Nightlife Areas". Urban Studies 511 (2014): 170-184. doi: 10.1177/0042098013484532

An exploration of young people's drinking in Zurich, Switzerland, with a focus on both public squares away from nightlife areas, referred to as 'square street drinking' and on the street within the vicinity of nightclubs, termed 'club street drinking'. The paper takes a relational space approach, and adds a social perspective to the dominant economic-political perspective of drinking in urban nightlife zones.

Duff, Cameron. "Accounting for Context: Exploring the Role of Objects and Spaces in the Consumption of Alcohol and other Drugs". Social and Cultural Geography. 132 (2012): 145-159. doi: 10.1080/14649365.2012.655765

Drawing on Actor-Network Theory, this paper analyses qualitative data collected into alcohol and drug consumption in Melbourne, Australia, and Vancouver, Canada. The paper is important in demonstrating that the consumption of alcohol and drugs is relational, involving diverse objects, spaces, actors and affects.

Foster, John, and Bob Heyman. "Drinking Alcohol at Home and in Public Places and the Time Framing of Risks". Health, Risk \& Society 15 6-7 (2013): 511-524. doi: 10.1080/13698575.2013.839779

Findings are presented from a qualitative study, which explores young people's, aged $13+$, and adult's, accounts of drinking away from licensed premises, either at home or in public places such as parks. The paper highlights that young people associate drinking away from licensed premises as being associated with immediate risks, including: fights. falls, and extreme intoxication. 
Holloway, Sarah, Mark Jayne, and Gill Valentine. "Sainsbury's is my Local': English Alcohol Policy, Domestic Drinking Practices and the Meaning of Home". Transactions of the Institute of British Geographers. 334 (2008): 532-547. doi: 10.1177/0309132507087649

A showcase of human geographical contributions to the study of alcohol, drinking and drunkenness. Attention is given to geographical engagements with complex interpenetrations of political, economic, social, cultural and spatial issues. Further, the importance of unpacking connections, similarities, differences and mobilities between supranational, national, regional and local spatial scales is brought to the fore. The paper highlights that such an approach represents a conceptually and empirically important contribution to alcohol studies research.

Galloway, Josie, Alasdair Forsyth, and David Shewan. Young People's Street Drinking Behaviour: Investigating the Influence of Marketing \& Subculture. [Online], Available: http://www.sccjr.ac.uk/wpcontent/uploads/2008/11/Young_Peoples_Street_Drinking_Behaviour.pdf [25th March 2018]. 2007.

This qualitative study, using focus groups, examines the street drinking behaviour of young adults (aged between 16 and 25). The study provides further knowledge about patterns of offtrade outdoor drinking culture among drinkers. The investigation also outlines which alcohol products are preferred by these individuals and why, paying attention to the roles of alcohol marketing and sub-cultural beliefs as factors affecting consumer choices.

Pennay, Amy, and Robin Room. "Prohibiting Public Drinking in Urban Public Spaces: A Review of the Evidence". Drugs: Education, Prevention and Policy. 1922 (2012): 91-101. doi: 10.3109/09687637.2011.640719

A review of community-based evaluations of street drinking bans, with a view to understanding the effectiveness of these laws in reducing alcohol-related harm and benefiting the community.

Townshend, Tim. and Marion Roberts. "Affordances, Young People, Parks and Alcohol Consumption". Journal of Urban Design 184 (2013): 494-516. doi: 10.1080/13574809.2013.835696

This paper is drawn from a larger research project exploring young people, leisure activities and alcohol consumption. The paper argues that the park is the most important place for young people to socialise outside the home. We hear from the voices of young people, who assert that drinking in the park is a relatively harmless activity, and they consider that they are often harshly judged. 
Wilkinson, Samantha. Young People's Drinking Geographies. In Horton, John, Bethan Evans, and Tracey Skelton. (Eds.) Geographies of Children and Young People. Play, Recreation, Health and Well Being. 9. Of Skelton, Tracey. (Ed.) Geographies of Children and Young People. Singapore: Springer. pp. 447-465, 2015.

A synthesis of existing literature, from a range of international contexts, which brings to the fore the diverse microgeographies within which young people consume alcohol, whilst also offering insight into how young people manage their well-being in such spaces.

\section{Young People's Alcohol-Related Urban Im/Mobilities}

The importance of im/mobilities for young people's identity formation is the focus of Skelton's 2013 work. Young people's alcohol-related mobilities have been under researched; yet, this section collates literature that goes some way towards addressing the treatment of drinking spaces in the academic literature as static, bounded, terrains. Drink walking, that is, walking in a public place whilst intoxicated, is the focus of Gannon et al.'s 2014 work. Yet, this paper does not deal with the embodied and emotional aspects of alcohol-related mobilities. This is something Jayne et al. 2012 seeks to address through a focus on the embodied experiences of backpacking mobilities, and the role of alcohol in producing (dis)comfort. Further, Duff and Moore 2015 explore young people's experiences as passengers on various forms of transport, bound up with the consumption of alcohol. Wilkinson 2017 seeks to work at the intersection of mobilities and hyperdiversity to demonstrate how young people are diverse in terms of alcohol consumption attitudes, behaviours and practices.

Duff, Cameron, and Moore, David. "Going Out, Getting About: Atmospheres of Mobility in Melbourne's Night-Time Economy”. Social \& Cultural Geography. $16 \quad 3$ (2015): 299-314. doi: 10.1080/14649365.2014.979864

An exploration of the atmospheres of mobility for young people residing in the inner city who take trams, walk or cycle to nearby venues, along with young people from periurban communities; that is, communities immediately adjoining an urban area, who use trains, buses or taxis to travel to, and from, venues in the inner city. This paper goes some way towards redressing the dearth of attention directed towards the embodied aspects of alcohol-related mobilities. 
Gannon, Billy, Lisa Rosta, Maria Reeve, Melissa Hyde, and lona Lewis, "Does it Matter Whether Friends, Parents, or Peers Drink Walk? Identifying which Normative Influences Predict Young Pedestrian's Decisions to Walk While Intoxicated". Transportation Research Part F. 22 (2014): 12-24. doi: 10.1016/j.trf.2013.10.007

An investigation into the role of different normative influences and perceived risk in predicting young people's self-reported drink walking intentions. The findings are important in providing a clearer indication of the normative influences and gender differences in young pedestrian's decisions to walk whilst intoxicated. Such findings can be utilised to inform future interventions designed to reduce injuries and fatalities associated with drink walking.

Jayne, Mark, Chris Gibson, Gordon Waitt, and Gill Valentine. "Drunken Mobilities: Backpackers, Alcohol, 'Doing Place'”. Tourist Studies. 123 (2012): 211-231. doi: 10.1177/1468797612461082

This paper enhances understandings of the role of alcohol, drinking and drunkenness as an important, and under-researched, element of tourism. The paper works at the intersection of three bodies of literature: mundane mobilities; performativities of tourism; and geographies of alcohol, drinking and drunkenness, and draws on empirical research undertaken in Australia, to highlight how alcohol, drinking and drunkenness are key to backpacking holidays.

Skelton, Tracey. "Young People's Urban Im/Mobilities: Relationality and Identity Formation". Urban Studies. 503 (2013): 467-483. doi: 10.1177/0042098012468893

This paper focuses on young people's local experiences of urban im/mobilities. It challenges the lack of attention afforded to young people by urban studies. Utilising two of mobility studies' conceptualisations, relationality and identity formation, the paper examines young Aucklanders' im/mobilities through urban space.

Wilkinson, Samantha. "Young People's Drinking Spaces and Im/Mobilities: A Case of 'Hyper'-Diversity". Journal of Youth Studies. (2017): doi: 10.1080/13676261.2017.1420763

Drawing on a 'palette' of interdisciplinary methods, the paper explores young people's alcohol consumption practices and experiences in the hyper-diverse suburban locations of Chorlton and Wythenshawe, Manchester, UK. The paper enhances understandings of hyper-diversity by elucidating the ways in which young people's everynight alcohol-related mobilities and diversity interpenetrate each other. The paper shows how young people are hyper-diverse in terms of their alcohol-related lifestyles, attitudes, and activities. 


\section{Relational Drinking Practices}

Drinking identities are relational; they develop and operate in relation to other identities. Intragenerational drinking relationships have been explored by De Visser et al. 2013, Maclean 2016, and Törrönen and Maunu 2011; the authors investigate the role of alcohol consumption in constituting friendship. The focus of Kothari et al. 2014 and Low et al. 2012 is the role of siblings in shaping drinking practices and experiences. Valentine et al. 2010 and Valentine et al. 2012 focus on intergenerationality and alcohol consumption; the first paper focuses on similarities and differences in drinking between generational cohorts, whereas the second paper focuses on familial transitions of norms and cultures surrounding. Thurnell-Read's 2013 paper looks at extra-familial intergenerational alcohol consumption practices, by comparing two stereotypes of male drinking bodies.

De Visser, Richard, Zoe Wheeler, Charles Abraham, and Jonathan Smith. "Drinking is our Modern Way of Bonding": Young People's Beliefs about Interventions to Encourage Moderate Drinking". Psychology \& Health. 2812 (2013):1460-1480. doi: 10.1080/08870446.2013.828293

An examination of age and gender differences in drinking motivations, to inform the development of targeted interventions to reduce alcohol-related harm. Interestingly, the paper highlights that negative aspects of alcohol consumption, including: caring for drunk friends, being cared for when intoxicated, and suffering through hangovers with friends, offer opportunities for interpersonal bonding.

Kothari, Brianne, Paul Sorenson, Lew Bank, and Jim Snyder. "Alcohol and Substance Use in Adolescence and Young Adulthood: The Role of Siblings". Journal of Family Social Work. 174 (2014): 324-343. doi: 10.1080/10522158.2014.924457

An examination of siblings' roles in alcohol and substance use patterns and trajectories in the context of both familial and non-familial factors across time. The paper is important in highlighting that there are strong associations between older and younger siblings' alcohol and substance consumption.

Low, Sabina, Joann Shortt, and James Snyder. "Sibling Influences on Adolescent Substance Use: The Role of Modeling, Collusion, and Conflict”. Development and Psychopathology. 241 (2012): 287-300. doi:

An examination of the longitudinal associations of older sibling substance use, and dyadic sibling conflict and collusion to younger sibling substance use. The paper argues that older sibling substance use has a direct effect on younger sibling use, but relationship dynamics and reinforcement have a fundamental role to play. 
MacLean, Sarah. "Alcohol and the Constitution of Friendship for Young Adults". Sociology 501 (2016) 93-108. doi: $10.1177 / 0038038514557913$

In the context of Melbourne, Australia, this paper offers an exploration of alcohol as a technology in young adults' friendship-making. The paper highlights that alcohol can build intimacy, particularly when similar levels of drunkenness are achieved. The paper highlights that understanding the importance of friendship-making in alcohol consumption helps to explain the persistence of heavy drinking and opportunities for harm reduction.

Thurnell-Read, Thomas. 'Yobs' and 'Snobs': Embodying Drink and the Problematic Male Drinking Body". Sociological Research Online. 182 (2013): 1-18. doi: 10.5153/sro.3000

This paper discusses two cultural stereotypes relating to male drinking bodies; these are, the 'lager lout', and the 'real ale enthusiast', which are typically associated with young and old drinking masculinities, respectively. The paper is novel in focusing on extrafamilial intergenerationality.

Törrönen, Jukka, and Antti Maunu. "Friendship and Social Emotions in Young Adult Finns' Drinking Diaries". Sociological Research Online 161 (2011): 1-17. doi: 10.5153/sro.2278

An exploration of the management of social emotions and friendship bonds, through an analysis young adults' pub and drinking diaries. The paper analyses alcohol consumption experiences from the vantage point of pride and shame, which brings to the fore how drinking strengthens or weakens different kinds of social relations and dynamics and how actors try to attach to them, or separate from them.

Valentine, Gill, Sarah Holloway, and Mark Jayne. "Generational Patterns of Alcohol Consumption: Continuity and Change". Health \& Place 165 (2010):916-925. doi: 10.1016/j.healthplace.2010.05.003 This paper provide insight into patterns of intergenerational change and continuity in drinking. The authors contend that the most significant differences in patterns of alcohol consumption articulated by the majority population in each generation cohort occurred - not between the mid (35-54) and young generation (aged 18-24) - but between the older (over 60) and mid generations.

Valentine, Gill, Mark Jayne, and Myles Gould. "Do As I Say, Not As I Do: The Affective Space of Family Life and The Generational Transmission of Drinking Cultures". Environment and Planning A. 444 (2012): 776-792. doi: 10.1068/a4446

An examination of the alcohol consumption practices parents model to their children (aged 512) through everyday family life. The authors find that parents transmit messages about when, and where, it is appropriate to consume alcohol through their own consumption practices. Additionally, the authors highlight that parents intentionally model drinking practices to their children by encouraging them to try alcohol. 